\title{
Assessment of Errors during Inhaler Usage among Asthma and COPD Patients
}

\author{
Binuraj C. ${ }^{1}$, Jeswin Jose ${ }^{2}$, Fathimath Dilsha ${ }^{3}$, Sreelakshmi P. ${ }^{4}$, Sareena A. ${ }^{5}$
}

${ }^{1}$ Department of Pulmonary Medicine, KMCT Medical College, Mukkam, Kerala, India. ${ }^{2}$ Department of Pharmacy Practice, KMCT Medical College, Mukkam, Kerala, India. ${ }^{3}$ Department of Pharmacy Practice, KMCT Medical College,

Mukkam, Kerala, India. ${ }^{4}$ Department of Pharmacy Practice, KMCT Medical College, Mukkam, Kerala, India.

${ }^{5}$ Department of Pharmacy Practice, KMCT Medical College, Mukkam, Kerala, India.

\section{ABSTRACT}

\section{BACKGROUND}

The cornerstone therapy for respiratory diseases is drugs for inhalation. Effectiveness of inhalers can be influenced by factors such as gender, age, educational status, and type of inhaler used and correct inhalation technique. The aim of this study is to provide information about common errors in technique that occur during inhalation.

\section{METHODS}

Male and female patients who met the inclusion criteria (age 18 - 80) years, using inhalers particularly MDI and DPI were included in the study. The study patients were asked to perform inhalation technique and the errors in technique that occur during inhalation were recorded. The sample size was 150 and duration of study was 6 months.

\section{RESULTS}

The common errors during the use of inhalers included, no exhalation before inhalation, no breath hold, and absence of proper washing of mouth after inhalation. Among the 86 MDI users, no exhalation before inhalation $(n=50)$, no breath hold $(n=35)$ and absence of proper washing of mouth after inhalation $(n=21)$. For the 64 patients using DPI, no exhalation before inhalation $(n=68)$, no breath hold $(n=51)$ and absence of proper washing of mouth after inhalation $(n=35)$.

\section{CONCLUSIONS}

For effective management of respiratory disease like asthma and COPD proper use of inhalers along with appropriate counseling is important.
Corresponding Author:

Dr. Binuraj C.,

Associate Professor,

Department of Pulmonary Medicine,

KMCT Medical College

Calicut, Kerala, India.

E-mail:drbinuraj2005@gmail.com

DOI: $10.14260 /$ jemds $/ 2020 / 4$

Financial or Other Competing Interests: None.

How to Cite This Article:

Binuraj C, Jose J, Dilsha F, et al. Assessment of errors during inhaler usage among asthma and COPD patients. J. Evolution Med. Dent. Sci. 2020;9(01):14-17, DOI: $10.14260 / \mathrm{jemds} / 2020 / 4$

Submission 11-11-2019,

Peer Review 20-12-2019,

Acceptance 27-12-2019,

Published 06-01-2020.

\section{KEY WORDS}

Asthma, COPD, Dry Powder Inhaler, Metered Dose Inhaler 


\section{BACKGROUND}

Asthma is a chronic disease characterized by recurrent attacks of breathlessness and wheezing. ${ }^{[1]}$ The global asthma 2018 report suggests that asthma kills around 1000 people every day and affects 339 million people.[2] COPD is a general term that describes progressive respiratory disease like emphysema and chronic bronchitis.[3] The cornerstone therapy for respiratory diseases is drugs for inhalation. ${ }^{[4,5]}$ The principle vehicles for effective administration of medications are inhalers. ${ }^{[6]}$ Effectiveness of inhalers can be influenced by factors such as age, gender, educational status, type of inhaler used, and the proper use of inhalers. Three main categories of inhalers include Pressurized Metered Dose Inhalers (pMDIs), Dry Powder Inhalers (DPIs) and Small Volume Nebulizers (SVNs).[7,8] However MDIs and DPIs are the most commonly used inhalers for disease conditions like Asthma and COPD.[8] Inhalers allow high lung deposition of the drug and minimize the loss of drugs through systemic bioavailability, and thereby reducing possible adverse drug reactions. DPIs were used till from 1970s and have made the inhalation technique much easier. DPIs are easier to use than pMDIs because they are breath activated, and also environmentally unfriendly propellants are not present in DPIs and DPIs do not produce a cold sensation during inhalation.[9,10] The effectiveness of drugs for inhalation such as beta 2 -agonists, corticosteroids, can be influenced by factors such as age, gender, educational status, type of inhaler used, and the proper use of inhalers. [1115] Many elderly people have poor inhalation techniques due diseases like arthritis, diminished vision. ${ }^{[16]}$ Correct inhalation technique is needed for effective management of disease like Asthma and COPD since improper use of inhalers may results in diminished therapeutic effect, resulting in poor control of symptoms and thereby leading to improper disease management.[17] The net result of this practice is that patient might receive treatment, but they lack proper education and training in correct inhalation technique, and thus the therapeutic effect of the patient is less than optimal.[11-13,18,19] The technical features of inhalers have improved constantly, but the delivery of the drug to the lungs depends upon correctly performed inhalation technique. Both DPIs and MDIs contain eight to ten steps and these steps must be performed correctly otherwise these may results in decreased therapeutic effect. Selection of inhaler device must be based on the availability, cost of the device, patient and physician preference etc. Also, patients still tend to have poor practice of inhalers; hence health professionals and patients must be adequately educated and trained about the correct steps in the use of inhalers.[15,20] The aim of this study is to provide information about errors that occur during the use inhalers.

\section{METHODS}

A prospective interventional study was conducted on a minimum of 150 patients the sample size was calculated with the help of a bio- statistician. We used percentage of practice and prevalence as the base information for our calculating sample size. The study was for duration of 6 months in 700 bedded tertiary care hospital, department of pulmonology. Male and Female patients who met the inclusion criteria (Age
18-80) years, using inhalers particularly MDI and DPI were included in the study. Age related physiological changes includes like lung capacity, bronchial muscle elasticity are all different among population. With increasing age, the FEV1 value decreases by around $30 \mathrm{ml}$ and proper inhalation of the patients will be altered and this FEV1 value can be decreased by 3-4 times among smokers. Hence the scoring was done accordingly. The study patients were asked to perform inhalation technique and the errors that occur during inhalation technique was recorded., we cross-examined the patients with the conventional, officially accepted steps for using MDIs and DPIs and each step was recorded and mistakes thay occur during inhalation was noted. Patients were properly counseled by health care professionals about the correct inhalation technique and were discharged.

Statistical analysis was done using PASW/SPSS.

\section{Steps for Correct usage of MDI}

\begin{tabular}{|c|c|}
\hline Sl. No. & Steps for Correct Usage of MDI \\
\hline S1 & Remove the cap \\
\hline S2 & Shake the inhaler \\
\hline S3 & Lock the lips appropriately around the mouthpiece \\
\hline S4 & Hold the MDI properly \\
\hline S5 & Inhale as soon as the canister is pressed \\
\hline S6 & Taking a deep breath slowly and deeply \\
\hline S7 & Hold the inhaled air for 5-10 seconds \\
\hline S8 & Re shake the inhaler for second puff \\
\hline S9 & Rinse well after inhalation \\
\hline S10 & Table 1. Steps for Correct Usage of MDI ${ }^{[6]}$ \\
\hline \multicolumn{2}{|c}{} \\
\hline
\end{tabular}

\section{Steps for Correct usage of DPI}

\begin{tabular}{|c|c|}
\hline Sl. No. & Steps for Correct Usage of DPI \\
\hline S1 & Remove the cap \\
\hline S2 & Load a dose of medicine \\
\hline S3 & Close the mouthpiece firmly \\
\hline S4 & Exhale fully \\
\hline S5 & Sit or stand upright, and breathe deeply as you can \\
\hline S6 & When done correctly, a vibration sound is heard \\
\hline S7 & Hold the inhaled air for 5-10 seconds \\
\hline S8 & After the use discard the Rota caps \\
\hline S9 & Wait about 1 minute before the next dose \\
\hline S10 & Rinse well after inhalation \\
\hline \multicolumn{2}{|c|}{} \\
\hline
\end{tabular}

\section{RESULTS}

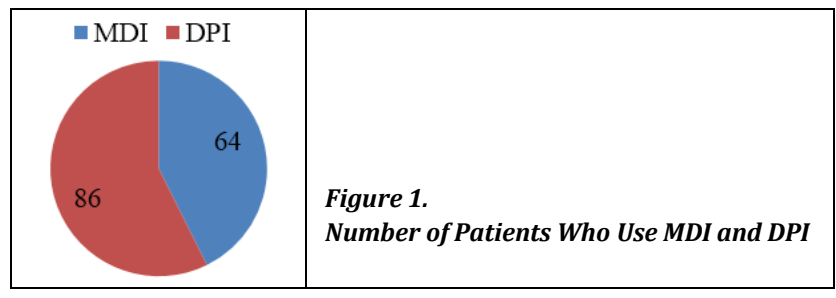

\section{Frequent Errors during MDI Usage}

The most frequent error was found to be no exhalation before inhalation. The second most frequent error was no breath hold. The third most frequent error was not proper washing of mouth after inhalation.

\section{Frequent Errors during DPI Usage}

The most frequent error was found to be no exhalation before inhalation. The second most frequent error was no breath 
hold. The third most frequent error was not proper washing of mouth after inhalation.
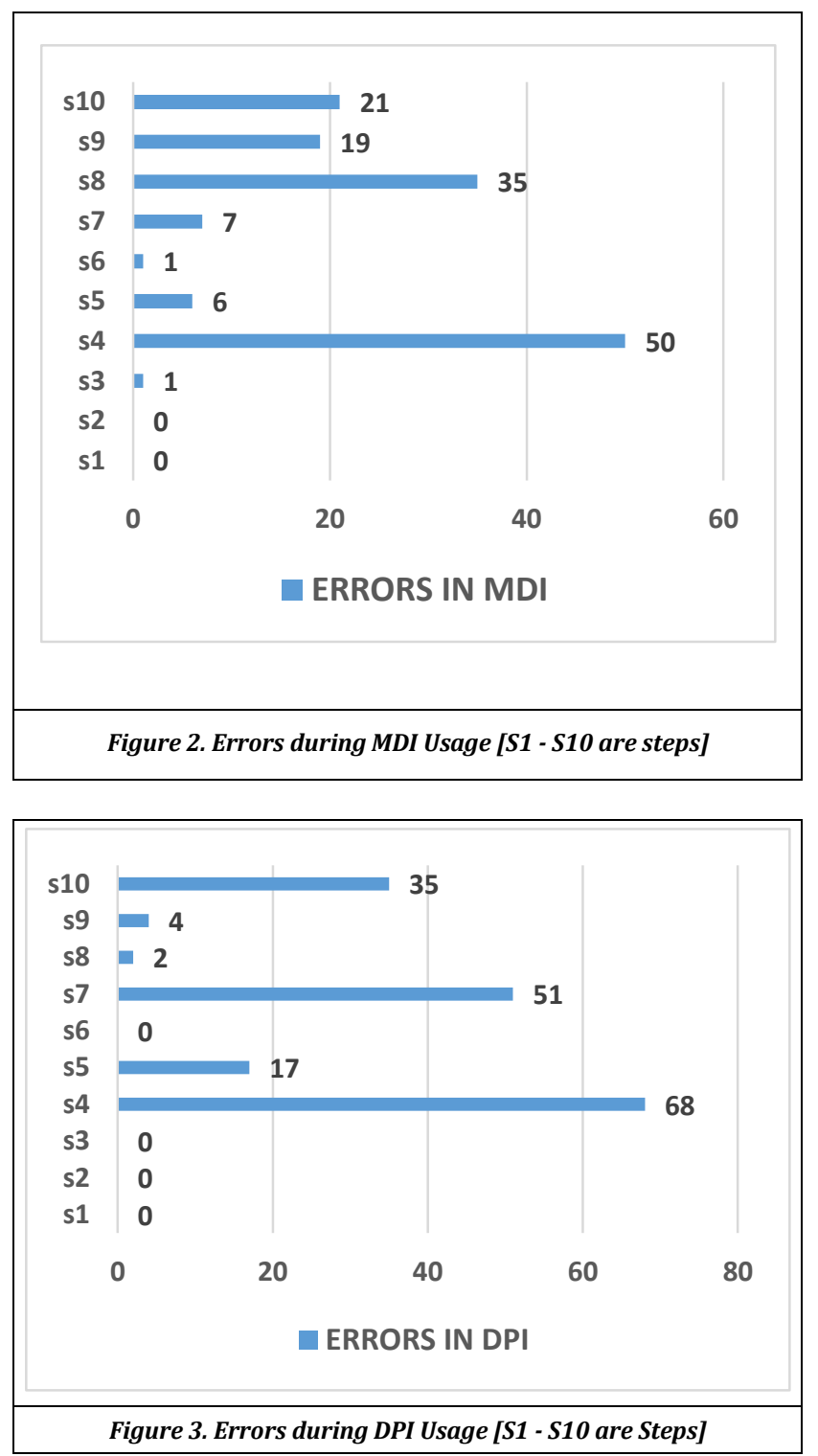

\section{DISCUSSION}

From our study we found that 86 of the patients were using DPIs and 64 of the patients were using MDIs, this was in correlation with the study of Lavorini et al. Furthermore, common errors made by large proportion of the patients were no exhalation before inhalation, second most frequent error was no proper breath hold, and the third most frequent error was not proper washing of mouth after inhalation. Patients using steroid type Inhalers must wash their mouth properly in order to prevent oral candidiasis; these results were in correlation with the study of Lavorini et al. From Robert et al study shows that most relevant challenges regarding the use of inhalers are possible impairment to physical skills for inhaler usage and cognitive ability for learning inhaler techniques and also elderly patients may have reduced financial income together with increased medication needs that place constraints on health care expenditures. These type of errors leads to improper delivery of drug which in turn leads to inappropriate control of disease like Asthma and COPD. Patient's inability to use inhalers correctly may be a direct consequence of insufficient or poor inhaler technique instruction. Proper training of inhalers results in good control over diseases, but these training sessions must be repeated at regular intervals and should be checked properly. For proper use of inhalers written instructions alone is inadequate, verbal instructions along with technique assessment and reassessment is needed. Interestingly patients who might receive multiple instructions regarding the use of inhalers shows well decrease in disease than those who receive single instruction regarding the use of inhalers. Appropriate training is more important than verbal or written instructions. Medical professionals who provide inhalers are lacking in basic knowledge to provide instruction about the proper use of inhalers, this might contribute to patient's poor technique when using these devices. Patients should have good assess to demonstration techniques in order to perform inhalation techniques properly. Proper education by health care providers and clinical pharmacist improves inhalation techniques of patients.

\section{CONCLUSIONS}

Frequent errors that occur during the use of inhalers are- no exhalation before inhalation, no proper breath hold, absence of proper washing of mouth after inhalation. Appropriate instructions provided by health care professionals regarding the use of inhalers reduces these frequent errors and diseases like asthma and COPD can be efficiently controlled.

\section{Limitations}

The study was done in a tertiary care center and the results may therefore not be generalizable to all Asthma and COPD patients in the community. Duration of the study was limited. Long term follow up is necessary to get more reliable data and also the sample size of the study was small and in future inhaler devices should be provided with visual and auditory feedback and a dose counter which resets after a correct inhalation movement confirming not only inhalation has occurred, but also that an inhalation is sufficient to deliver the drug. With the introduction of these types of inhaler devices diseases like asthma and COPD can be controlled efficiently in near future.

\section{ACKNOWLEDGEMENT}

Authors thank the patients who participated in the study.

\section{REFERENCES}

[1] Shyam RM, Jyothi D, Prasad DTS, et al. Role of clinical pharmacist in impact of patient counselling in asthmatic patients. Journal of Global Trends in Pharmaceutical Sciences 2013;4(2):1111-7. 
[2] Global asthma report 2018. Geneva: Asthma report 2018. [Cited 2019 Oct, 31]. http://www.globalasthmareport.org.

[3] World Health Organization. Geneva: Chronic Obstructive Lung Disease, [Cited 2019, Nov 11]. https://www.who.int/respiratory/copd/en/

[4] Crompton G. A brief history of inhaled asthma therapy over the last fifty years. Prim Care Respir J 2006;15(6):326-31.

[5] Cochrane MG, Bala MV, Downs KE, et al. Inhaled corticosteroids for asthma therapy. Patient compliance, devices and inhalation technique. Chest 2000;117(2):542-50.

[6] Suthar J, Patel ZA, Shelat B, et al. Assessment of inhalation techniques in COPD and asthma patients using metered dose inhaler and rota-haler. Indian Journal of Pharmacy Practice 2019;12(4):217-24.

[7] Van der Palen J, Klein JJ, Kerkhoff AH, et al. Evaluation of the effectiveness of four different inhalers in patients with chronic obstructive pulmonary disease. Thorax 1995;50(11):1183-7.

[8] Lavorini F, Magnan A, Dubus JC, et al. Effect of incorrect use of dry powder inhalers on management of patients with asthma and COPD. Respiratory Medicine 2008;102(4):593-604.

[9] Newman SP, Busse WW. Evolution of dry powder inhaler design, formulation and performance. Respir Med 2002;96(5):293-304.

[10] Crompton GK. Problems patients have using pressurized aerosol inhalers. Eur J Respir Dis Suppl 1982;119:101-4.

[11] Hesselink AE, Penninx BWJH, Wijnhoven HA, et al. Determinants of an incorrect inhalation technique in patients with asthma or COPD. Scan J Prim Health Care 2001;19(4):255-60.
[12] Pedersen S, Frost L, Arnfred T. Errors in inhalation technique and efficiency in inhaler use in asthmatic children. Allergy 1986;41(2):118-24.

[13] Goren A, Noviski N, Avital A, et al. Assessment of the ability of young children to use a powder inhaler device (Turbuhaler). Pediatr Pulmonol 1994;18(2):77-80.

[14] Brocklebank D, Wright J, Cates C. Systematic review of clinical effectiveness of pressurised metered dose inhalers versus other hand held inhaler devices for delivering corticosteroids in asthma. BMJ 2001;323(7318):896-900.

[15] Van der Palen J, Klein JJ, van Herwaarden CL, et al. Multiple inhalers confuse asthma patients. Eur Respir J 1999;14(5):1034-7.

[16] Franks M, Briggs P. Use of a cognitive ergonomics approach to compare usability of a multidose dry powder inhaler and a capsule dry powder inhaler: an open-label, randomized, controlled study. Clin Ther 2004;26(11):1791-9.

[17] Moller M, Fritsche D, Rivera D, et al. Improvement of asthma therapy by a novel budesonide multidose dry powder inhaler. Arzneimittelforschung 2003;53(8):5627.

[18] Molimard M, Rahersion C, Lignot S, et al. Assessment of handling of inhaler devices in real life: an observational study in 3811 patients in primary care. J Aerosol Med 2003;16(3):249-54.

[19] Diamond SA, Chapman KR. The impact of a nationally coordinated pharmacy-based asthma education intervention. Can Respir J 2001;8(4):261-5.

[20] Crompton GK, Barnes PJ, Broeders M, et al. The need to improve inhalation technique in Europe: a report from the Aerosol Drug Management Improvement Team. Resp Med 2006;100(9):1479-94. 